\title{
INFLUÊNCIA DA FORMA E POSIÇÃO DA ENCOSTA NAS CARACTERÍSTICAS DO SOLO E NA REGENERAÇÃO NATURAL EM ÁREAS DE PASTAGEM ABANDONADAS ${ }^{1}$
}

\author{
HILL SLOPE FORM AND POSITION INFLUENCE IN SOIL CHARACTERISTICS AND NATURAL \\ REGENERATION OF ABANDONED PASTURES AREAS
}

\author{
Alessandro de Paula Silva ${ }^{2}$ Alexander Silva de Resende ${ }^{3}$ Guilherme Montandon Chaer ${ }^{4}$ Fernando \\ Lima Aires Gonçalves ${ }^{5}$ Eduardo Francia Carneiro Campello ${ }^{3}$
}

\begin{abstract}
RESUMO
O objetivo desse trabalho foi avaliar a influência do relevo nas características químicas e físico-hídricas do solo e na regeneração natural, em áreas de pastagens abandonadas. Para o estudo foram consideradas oito áreas de relevo movimentado no município de Itaboraí-RJ, em cada uma das áreas foram selecionadas duas topossequências divididas em terços superior, médio e inferior, contemplando as pedoformas côncavas e convexas. Foram instaladas duas parcelas $(20 \mathrm{~m} \times 10 \mathrm{~m}) \mathrm{em}$ cada terço, uma para cada pedoforma, nas quais se avaliaram os atributos físico-hídricos e químicos do solo, a regeneração natural e a biomassa aérea da pastagem (biomassa estocada e taxa de rebrota). $\mathrm{O}$ terço superior apresentou os menores teores de argila e as características químicas não foram influenciadas pela posição na encosta. Na pedoforma côncava, nas áreas de textura argilosa, obtiveram-se menores valores de soma de bases trocáveis e de carbono, quando comparada à pedoforma convexa, de mesma classe textural. Essa tendência se repetiu, porém, de forma não significativa, nas áreas com textura média. As características físico-hídricas estiveram mais associadas à granulometria do solo que à posição na paisagem. A regeneração natural apresentou poucas espécies $\mathrm{e}$ não foram observadas diferenças tanto para a posição na encosta como para a pedoforma. No entanto, a espécie de Poaceae existente na pastagem de cada área foi um indicador mais sensível do potencial de desenvolvimento da regeneração natural do que as características edáficas, com destaque negativo para a paisagem dominada por Urochloa humidicola (Rendle) Morrone e Zuloaga, na qual se encontraram os menores valores de regeneração natural.
\end{abstract}

Palavras-chave: topossequência; pedoforma; dinâmica sucessional.

\section{ABSTRACT}

The aim of this work was to evaluate the influence of the topographic conditions on soil chemical and physico-hydric characteristics and on the natural regeneration of abandoned pasture areas. We studied eight areas of hill lands in the municipality Itaboraí - Rio de Janeiro State. Two topossequences were selected in each one of the areas. These topossequences were divided into shoulder, backslope and footslope positions contemplating the main landform, concave and convex. Two experimental plots (20 $\mathrm{x} 10 \mathrm{~m}$ ) were installed in each section of the toposequence, one for each landform, for the evaluation of soil chemical and physical-hydric characteristics, natural regeneration and pasture biomass (stocked

1 Parte da dissertação do primeiro autor apresentada ao Programa de Pós-Graduação em Agronomia - Ciência do Solo, Universidade Federal Rural do Rio de Janeiro (PPGA-CS/UFRRJ)

2 Engenheiro Florestal, Dr., Professor do Instituto Federal do Norte de Minas Gerais, Campus Salinas, Rod. MG-404, Km 2, Zona Rural, CEP 39560-000, Salinas (MG), Brasil. alessandro.silva@ifnmg.edu.br

3 Engenheiro Florestal, Dr., Pesquisador Embrapa Agrobiologia, Rod. BR 465, Km 7, Bairro Ecologia, CEP 23891000, Seropédica (RJ), Brasil. alexander.resende@embrapa.br / eduardo.campello@embrapa.br

4 Engenheiro Agrônomo, Dr., Pesquisador Embrapa Agrobiologia, Rod. BR 465, Km 7, Bairro Ecologia, CEP 23891000, Seropédica (RJ), Brasil. guilherme.chaer@embrapa.br

5 Engenheiro Florestal, MSc., Doutorando pelo Programa de Pós-Graduação em Ciências Ambientais e Florestais, Universidade Federal Rural do Rio de Janeiro, Rod. BR 465, Km 7, Bairro Ecologia, CEP 23890-000, Seropédica (RJ), Brasil. fernando_lima85@yahoo.com.br

Recebido para publicação em 9/05/2012 e aceito em 8/06/2017

Ci. Fl., v. 28, n. 3, jul. - set., 2018 
biomass and regrowth rate). Our results show that soil texture was influenced by landscape position, in which the shoulder had lower clay content. The chemical characteristics were not influenced by topographic conditions. The physico-hydric characteristics were influenced by the particle size of the soil. The natural regeneration presented few species, and was not influencied by its position in the landscape and by the landform. However, the development of natural regeneration tended to be more limited in pasture dominated by Urochloa humidicola (Rendle) Morrone e Zuloaga.

Keywords: toposequence; landform; successional dynamic.

\section{INTRODUÇÃO}

As atividades de restauração florestal têm ganhado importância nos últimos anos visando ao atendimento à legislação vigente, tanto na área periurbana como na rural. Dependendo das condições ambientais, o processo de recuperação pode ser bastante complexo e oneroso. Entre os grandes desafios dessa temática, a adoção de técnicas de revegetação eficazes e adequadas às peculiaridades do local a ser recuperado é um dos maiores (FERREIRA et al., 2007).

Entre os ambientes considerados complexos estão as encostas, que são caracterizadas por apresentarem declividades mais elevadas, o que dificulta e onera as operações de plantio e manutenção, devido, entre outros fatores, à dificuldade de acesso. Esses locais também são mais sujeitos aos efeitos do deficit hídrico do solo, sendo comum o menor desenvolvimento inicial das plantas nessa paisagem. Essa situação é diretamente influenciada pela posição que as plantas ocupam na encosta. O formato da pedoforma da encosta (côncava, convexa, etc.) é um fator que, por condicionar o regime de fluxo hídrico do solo e, consequentemente, distintas características químicas e físicas, acarreta também diferenças na diversidade e desenvolvimento das plantas (SOUZA, 2008). Dessa forma, estudos vêm sendo realizados em áreas com essas particularidades buscando entender a dinâmica de regeneração no intuito de desenvolver técnicas que possibilitem trabalhar de forma mais eficiente (CURCIO et al., 2006; SANTOS et al., 2016).

Visualmente, em áreas de pastagens abandonadas, o comportamento da regeneração natural se dá de forma distinta, principalmente entre as pedoformas côncavas e as convexas ou retilíneas. É comum a regeneração natural surgir em áreas côncavas em detrimento das demais pedoformas. Diante disso, objetivou-se com esse trabalho estudar e entender as razões que levam a esse padrão observado. Será que características químicas e físicas do solo em cada pedoforma podem condicionar esse processo, influenciando a produção de biomassa de capim e em consequência a regeneração natural? Será que há um fator mais sensível que o solo e que possa ser utilizado como indicador para predição do maior ou menor potencial de regeneração natural de uma área?

\section{MATERIAL E MÉTODOS}

\section{Caracterização da área}

O estudo foi realizado em Itaboraí, região metropolitana do estado do Rio de Janeiro próxima à baía de Guanabara e a Serra do Mar. A área está inserida nas bacias hidrográficas dos rios Macacu e Caceribu, entre as coordenadas geográficas $22^{\circ} 40^{\prime} 35^{\prime \prime} \mathrm{S}$ e $22^{\circ} 38^{\prime} 51^{\prime \prime} \mathrm{S}$ e, $42^{\circ} 47^{\prime} 35^{\prime \prime} \mathrm{W}$ e $42^{\circ} 49^{\prime} 20^{\prime \prime} \mathrm{W}$, na fitofisionomia Floresta Ombrófila Densa. O clima da região, segundo a classificação de Köppen é do tipo Aw, definido como clima tropical com inverno seco e verões chuvosos. A precipitação média da região é de $1.460 \mathrm{~mm}$ e a temperatura média de $21,4^{\circ} \mathrm{C}$.

Os fragmentos florestais existentes encontram-se em estágios de regeneração diferenciados e distribuídos de forma esparsa, emergidos na matriz pastagem, na qual predominam as espécies Urochloa humidicola (Rendle) Morrone e Zuloaga, Urochloa decumbens Stapf. (ambas sinonímias de Brachiaria) e Paspalum sp.. Essas pastagens ocupam desde planícies de inundação, caracterizadas por relevos predominantemente planos a suavemente ondulados até encostas com relevo forte ondulado. No local do estudo, a principal atividade econômica foi a pecuária extensiva por mais de 30 anos, havendo em muitas ocasiões superlotação das pastagens e prática de queimada para renovação das mesmas. Esses fatos 
desencadearam processos erosivos, principalmente nas áreas de maior declive. Isso perdurou até o ano de 2007, quando houve o abandono do local por desapropriação em razão de projeto de interesse público.

Para o estudo foram consideradas oito áreas no ano de 2010, com altitude de 58 a $90 \mathrm{~m}$. Em cada uma foram selecionadas duas topossequências, que foram divididas em terços superior, médio e inferior contemplando as pedoformas principais, côncavas e convexas, que foram separadas em campo a partir de observação visual. Todas as oito estavam sobre Latossolo Vermelho-Amarelo Distrocoeso típico variando somente os teores de argila e a declividade em que se encontravam (GOMES et al., 2014).

Em cada terço foram instaladas duas parcelas de dimensões $20 \mathrm{~m}$ x $10 \mathrm{~m}$, sendo uma para cada pedoforma, cujo maior lado foi disposto perpendicularmente à linha de declive. Ao todo foram estabelecidas seis parcelas por área, totalizando 48. Nessas parcelas foram realizadas as coletas de solo e determinada a declividade do terreno. A visão da área e o esquema de alocação de parcelas são demonstrados na Figura 1.
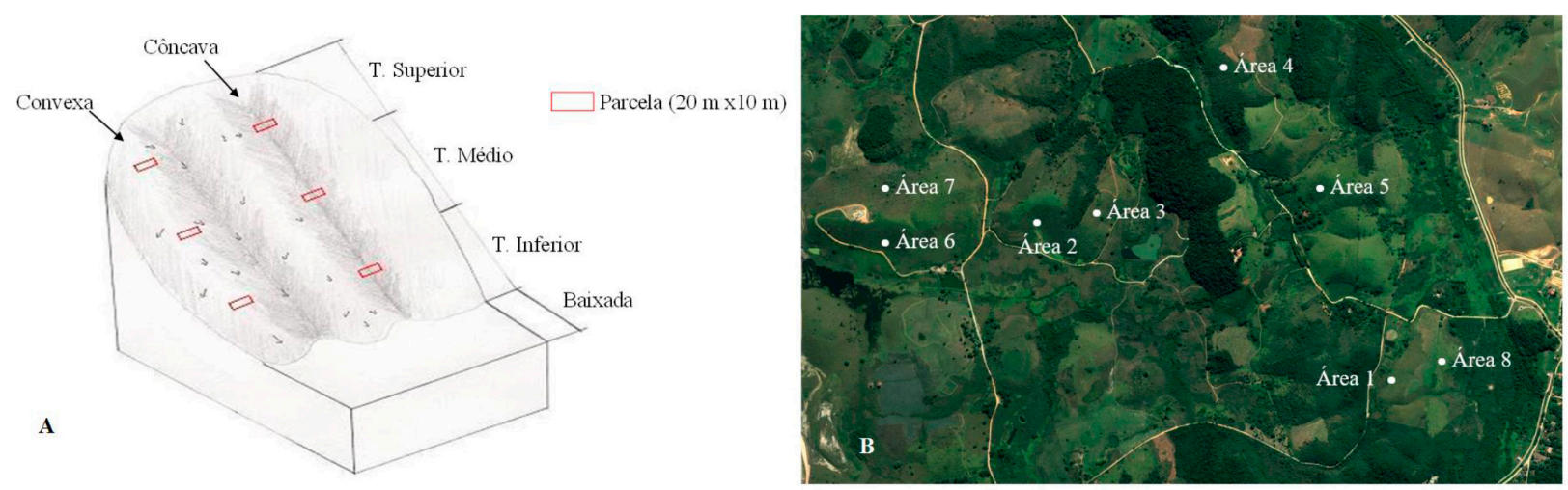

FIGURA 1: Ilustração esquemática das pedoformas, divisão da topossequência e das parcelas (A) e localização das áreas de estudo (B), Itaboraí-RJ. Fonte: Google Earth (Data da imagem: 28/08/2011).

FIGURE 1: Illustration of landforms, division of toposequence and plots (A) and location of study areas (B), Itaboraí, RJ state.

\section{Análises físico-hídricas do solo}

A análise físico-hídrica objetivou determinar a granulometria, a densidade, a porosidade (total, macro e micro), a condutividade hidráulica através de amostras indeformadas coletadas em três pontos de cada parcela, uma no centro e as demais nas extremidades, sendo considerado para tanto a profundidade de 0-0,10 m, as coletas se deram no centro de classe da referida camada. Utilizou-se amostrador de Kopeck, com anéis cilíndricos de altura e diâmetro de $0,05 \mathrm{~m}$. As coletas foram realizadas no mês de fevereiro de 2010 .

A condutividade hidráulica do solo saturado, a porosidade (total, macro e micro) e densidade do solo foram determinadas respectivamente pelos métodos do nível constante, da mesa de tensão (tensão de $6 \mathrm{kPa}$ ) e do anel volumétrico (EMBRAPA, 1997). A resistência mecânica do solo à penetração (RMSP) foi determinada com auxílio de um penetrógrafo Sc-60 da Soil Control, na profundidade de 0-0,10 m, em locais adjacentes aos locais de coleta das amostras indeformadas. Para essa avaliação, determinou-se a umidade do solo no momento da realização do teste.

A granulometria do solo foi determinada pelo método da pipeta (EMBRAPA, 1997) e Triângulo Textural (SANTOS et al., 2005). Na primeira etapa, realizou-se a dispersão química utilizando $\mathrm{NaOH}$ $0,1 \mathrm{~mol} \mathrm{~L}^{-1}$ como agente dispersante, seguindo a metodologia utilizada por Ruiz (2005). A segunda etapa constou de dispersão mecânica, realizada em agitador tipo Wagner a $60 \mathrm{rpm}$, por um período de 16 horas. 
Os teores de argila (diâmetro $<0,002 \mathrm{~mm}$ ) e areia (diâmetro entre 2 a $0,05 \mathrm{~mm}$ ) totais foram obtidos respectivamente pela pipetagem e peneiramento, enquanto o teor de silte (diâmetro entre 0,05 a $0,002 \mathrm{~mm}$ ) foi calculado pela diferença.

\section{Análise química do solo}

Para a análise química foram coletadas três amostras simples por parcela, também na camada de $0-0,10 \mathrm{~m}$, as quais originaram uma amostra composta. As amostras foram identificadas, secas ao ar, destorroadas, peneiradas em peneira de $2 \mathrm{~mm}$ de malha e encaminhadas ao Laboratório de Química Agrícola da Embrapa Agrobiologia para análise. A análise consistiu na determinação de $\mathrm{pH}$ em água na relação 1:2,5 (solo:água); $\mathrm{Al}, \mathrm{Ca}, \mathrm{Mg}$ (trocáveis extraídos com KCl $1 \mathrm{~mol} \mathrm{~L}^{-1}$, analisados por titulometria); $\mathrm{P}, \mathrm{K}$ (extraídos pelo extrator Mehlich-1 e analisados por colorimetria); C (titulometria oxirredução) e N (pelo método de Kjeldahl), possibilitando a determinação das saturações por base (V \%) e alumínio (m) e os valores de capacidade de troca de cátions potencial do solo a pH 7,0 (T) e soma de bases trocáveis (SB), segundo Embrapa (1997).

\section{Biomassa da pastagem e da regeneração natural}

Quantificou-se a biomassa existente e a taxa de rebrota da pastagem nos meses de fevereiro e novembro de 2010, respectivamente. Com auxílio de um gabarito de dimensões de $0,5 \mathrm{~m}$ x 0,5 $\mathrm{m}$ foi coletada toda a parte aérea da pastagem a $0,05 \mathrm{~m}$ do nível do solo, pesada em campo e retirada uma subamostra para a determinação do percentual de biomassa seca, sendo determinado pela secagem em estufa de ventilação forçada a $65^{\circ} \mathrm{C}$ até peso constante. Para a avaliação da taxa de rebrota da pastagem foi realizado o corte de uniformização na altura de $0,05 \mathrm{~m}$ do nível do solo, com auxílio de uma roçadeira costal. Decorridos 35 dias após o corte de uniformização, amostras da rebrota da pastagem foram coletadas para determinação da massa seca, seguindo a mesma altura de corte da determinação da biomassa existente. De posse desses valores, foi estimada a quantidade de biomassa seca da parte aérea da pastagem nas parcelas e extrapoladas por unidade de área, bem como a taxa de rebrota em $\mathrm{kg} \mathrm{ha}^{-1} \mathrm{dia}^{-1}$, nas distintas pedoformas e posições na encosta.

A análise da regeneração natural de espécies nativas foi feita com base na quantificação e identificação das espécies herbáceas, arbustivas e arbóreas nas parcelas. Para as espécies arbóreas, o trabalho foi feito de forma censitária em cada parcela. Para as espécies vegetais herbáceas e arbustivas a quantificação foi feita com base na avaliação visual da cobertura sobre o solo através de uma escala de 0 a 100, em que zero (0) representa nenhuma cobertura (nenhum indivíduo) e 100 a total cobertura da unidade amostral por essas espécies. De posse desses valores percentuais calculou-se a área ocupada por essas espécies/unidade de área $\left(\mathrm{m}^{2} \mathrm{ha}^{-1}\right)$. As espécies arbóreas foram identificadas em nível de família e mediu-se o diâmetro do coleto, $\mathrm{o}$ qual foi utilizado para cálculo da área basal ha ${ }^{-1}$ sendo designada como 'dominância'. Para ambos os grupos da regeneração foi determinada a riqueza de espécies a qual representa o número total de espécies em uma unidade amostral. 


\section{Análise dos dados}

Os dados foram submetidos aos testes de normalidade (Lilliefors, $5 \%$ ) e homogeneidade de variância (Cochran e Barttlet, 5 \%) com utilização do programa SAEG / versão 8.1. Em seguida procederam-se os testes de análise de variância e de comparação de médias (Tukey a $5 \%$ de probabilidade) pelo programa SISVAR.

\section{RESULTADOS E DISCUSSÃO}

\section{Meio físico e atributos físico-hídricos do solo}

Foi possível distinguir dois grupos de áreas quanto à textura do solo, sendo um (Grupo 1) correspondendo à textura argilosa (áreas 1, 4, 5 e 8) e outro (Grupo 2) com textura média (áreas 2, 3, 6 e 7), cujos teores médios de argila foram, respectivamente, de $432,14 \mathrm{~g} \mathrm{~kg}^{-1}$ e 291,03 $\mathrm{g} \mathrm{kg}^{-1}$. Com base nessa distinção, os dados foram agrupados e analisados considerando essa influência textural, admitindo que a declividade foi similar entre os grupos (Figura 2), uma vez que $92 \%$ das áreas dos dois grupos encontravamse nas classes forte ondulado a montanhoso. O histórico de ocupação e uso da terra foi o mesmo para todas as áreas.
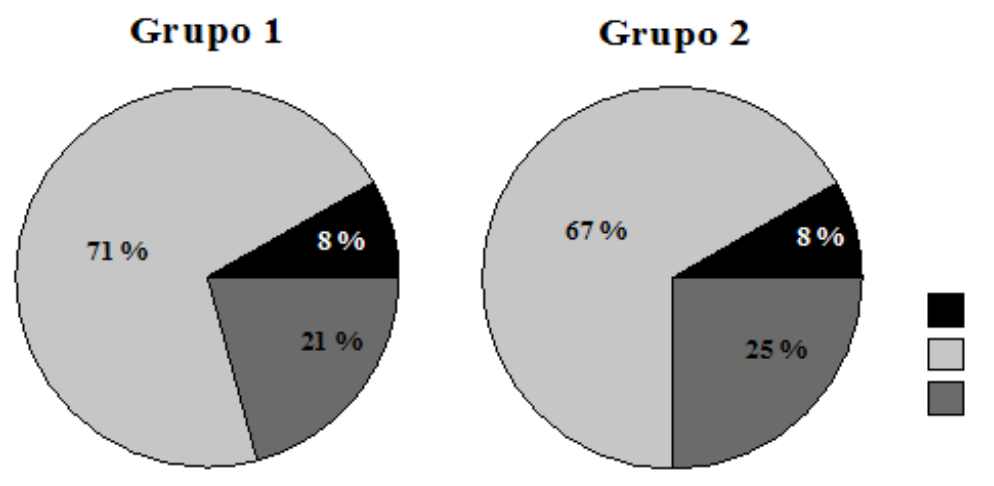

Ondulado (8 a $20 \%$ )

Forte ondulado (20 a $45 \%$ )

Montanhoso (45 a $75 \%)$

FIGURA 2: Classes de declividade média dos dois grupos de áreas avaliados, Itaboraí-RJ.

FIGURE 2: Classes of average slope of two groups of areas assessed, Itaboraí, RJ state.

O teor de argila apresentou padrão semelhante entre os dois grupos, quando considerada a posição na encosta, sendo maiores nos terços médio e inferior (Tabela 1). Tal padrão caracteriza o terço superior como zona de perda, na qual as argilas dispersas podem estar se acumulando nas partes mais baixas da encosta. Santos et al. (2016) estudando a influência das pedoformas nas propriedades físicas e químicas em topossequência, encontraram padrão semelhante para a camada de 0 a $0,05 \mathrm{~m}$. A respeito da influência do fator pedoforma, não foi constatado nenhum padrão entre os grupos com maior ou menor teor de argila. 
Silva, A. P. et al.

TABELA 1: Análise granulométrica das áreas estudadas separadas em grupos, Itaboraí-RJ.

TABLE 1: Particle size analysis of the studied areas separated by groups, Itaboraí, RJ state.

\begin{tabular}{|c|c|c|c|c|c|c|c|}
\hline \multirow{2}{*}{\multicolumn{2}{|c|}{ Posição na encosta }} & \multicolumn{3}{|c|}{ Grupo 1} & \multicolumn{3}{|c|}{ Grupo 2} \\
\hline & & Argila & Silte & Areia & $\overline{\text { Argila }}$ & Silte & Areia \\
\hline \multirow{4}{*}{ Superior } & Máximo & 515.6 & 192.9 & 672.1 & 337.3 & 1232 & 7901 \\
\hline & Mínimo & 238,4 & 67,4 & 322,6 & 156 & 42,6 & 546,2 \\
\hline & Mediana & 379,9 & 96,5 & 523,9 & 259,2 & 83,7 & 660,3 \\
\hline & Média & $387,3 \mathrm{Ab}$ & $111,1 \mathrm{Aa}$ & $501,6 \mathrm{Ba}$ & $255,5 \mathrm{Bb}$ & $80,0 \mathrm{Ba}$ & $664,4 \mathrm{Aa}$ \\
\hline \multirow{4}{*}{ Médio } & Máximo & 607,3 & 166,7 & 531,3 & 439,9 & 98,6 & 699,7 \\
\hline & Mínimo & 380,5 & 62,9 & 309,1 & 224,4 & 59 & 474,3 \\
\hline & Mediana & 454 & 93,3 & 463,6 & 321,3 & 83,2 & 609 \\
\hline & Média & $468,1 \mathrm{Aa}$ & $95,4 \mathrm{Ab}$ & $436,5 \mathrm{Bb}$ & $315,9 \mathrm{Ba}$ & $82,3 \mathrm{Aa}$ & $601,7 \mathrm{Ab}$ \\
\hline \multirow{4}{*}{ Inferior } & Máximo & 538,5 & 187,8 & 562,7 & 394,5 & 116,4 & 729,3 \\
\hline & Mínimo & 345,4 & 66 & 273,7 & 190,6 & 59,4 & 511,9 \\
\hline & Mediana & 431,4 & 100,6 & 471,9 & 310,5 & 77 & 610 \\
\hline & Média & $441,1 \mathrm{Aa}$ & $107,3 \mathrm{Aab}$ & $451,6 \mathrm{Bb}$ & $301,7 \mathrm{Ba}$ & $80,9 \mathrm{Ba}$ & $617,4 \mathrm{Aab}$ \\
\hline \multicolumn{8}{|c|}{ Pedoforma } \\
\hline \multirow{4}{*}{ Côncava } & Máximo & 607,3 & 141,5 & 563,7 & 394,5 & 123,2 & 790,1 \\
\hline & Mínimo & 340,4 & 62,9 & 309,1 & 156 & 42,6 & 537,2 \\
\hline & Mediana & 435,5 & 94,2 & 483,9 & 278,2 & 70,2 & 647,1 \\
\hline & Média & $453,0 \mathrm{Aa}$ & $93,4 \mathrm{Ab}$ & $453,6 \mathrm{Ba}$ & $277,6 \mathrm{Ba}$ & $75,0 \mathrm{Bb}$ & $647,4 \mathrm{Aa}$ \\
\hline \multirow{4}{*}{ Convexa } & Máximo & 538,5 & 192,9 & 672,1 & 439,9 & 116,4 & 763,8 \\
\hline & Mínimo & 238,4 & 67,4 & 273,7 & 170,6 & 56,8 & 474,3 \\
\hline & Mediana & 407,9 & 99,7 & 493 & 320 & 88,6 & 585,4 \\
\hline & Média & $411,3 \mathrm{Ab}$ & $115,8 \mathrm{Aa}$ & $472,9 \mathrm{Ba}$ & $304,5 \mathrm{Ba}$ & $87,2 \mathrm{Ba}$ & $608,3 \mathrm{Ab}$ \\
\hline \multicolumn{2}{|l|}{ Média } & 432,1 & 104,6 & 463,2 & 291 & 81,1 & 627,9 \\
\hline \multicolumn{2}{|c|}{ Coef. Variação (\%) } & 19 & 30 & 21 & 24 & 20 & 13 \\
\hline
\end{tabular}

Para a mesma variável, valores seguidos de mesma letra não diferem entre si pelo teste $\mathrm{F}$ (grupos e pedoforma) e Tukey (posição na encosta) a $5 \%$ de significância, em que letras maiúsculas e minúsculas indicam comparação, respectivamente, entre e dentro dos grupos.

As características físico-hídricas do Grupo 1, tanto em relação à posição na encosta (Tabela 2) quanto à pedoforma (Tabela 3), não diferiram estatisticamente. Para as áreas do Grupo 2, maiores valores de macroporosidade e porosidade total foram observados nos terços superior e médio, justamente quando os teores de areia foram maiores. As áreas mais argilosas (Grupo 1) apresentaram maior microporosidade e porosidade total quando comparadas às de textura média, que por sua vez apresentaram maior macroporosidade. 
TABELA 2: Efeito da posição na encosta e da pedoforma sobre as características físico-hídricas do solo das áreas avaliadas, Itaboraí-RJ.

TABLE 2: Effect of toposequence position and landform on soil physico-hydrical characteristics of the evaluated areas, Itaboraí, RJ state.

\begin{tabular}{|c|c|c|c|c|c|c|c|c|}
\hline & \multicolumn{8}{|c|}{ Áreas do Grupo 1} \\
\hline \multirow{2}{*}{\multicolumn{2}{|c|}{ Posição na encosta }} & \multicolumn{3}{|c|}{------ Porosidade $\left(\mathrm{m}^{3} \mathrm{~m}^{-3}\right)$------ } & \multirow{2}{*}{$\begin{array}{c}\text { Densidade } \\
\mathrm{Mg} \mathrm{m}^{-3}\end{array}$} & \multirow{2}{*}{$\begin{array}{c}\mathrm{K}(\theta) \\
\mathrm{cm} \mathrm{h}^{-1}\end{array}$} & \multirow{2}{*}{$\begin{array}{c}\text { RMSP } \\
\mathrm{MPa}\end{array}$} & \multirow{2}{*}{$\begin{array}{l}\mathrm{Ug} \\
\mathrm{g} \mathrm{g}^{-1}\end{array}$} \\
\hline & & Macro & Micro & Total & & & & \\
\hline \multirow{4}{*}{ Superior } & Máximo & 0,14 & 0,5 & 0,56 & 1,39 & 4,8 & 2,75 & 0,33 \\
\hline & Mínimo & 0,01 & 0,35 & 0,39 & 1,1 & 0,01 & 0,51 & 0,19 \\
\hline & Mediana & 0,04 & 0,42 & 0,46 & 1,29 & 0,52 & 1,4 & 0,24 \\
\hline & Média & $0,05 \mathrm{Ba}$ & $0,42 \mathrm{Aa}$ & $0,47 \mathrm{Aa}$ & $1,29 \mathrm{Aa}$ & $1,26 \mathrm{Ba}$ & $1,58 \mathrm{Aa}$ & 0,25 \\
\hline \multirow{4}{*}{ Médio } & Máximo & 0,15 & 0,49 & 0,52 & 1,39 & 19,64 & 3,47 & 0,34 \\
\hline & Mínimo & 0,01 & 0,34 & 0,39 & 1,16 & 0,22 & 1,05 & 0,19 \\
\hline & Mediana & 0,05 & 0,39 & 0,46 & 1,29 & 0,57 & 1,82 & 0,23 \\
\hline & Média & $0,06 \mathrm{Ba}$ & $0,40 \mathrm{Aa}$ & $0,46 \mathrm{Aa}$ & $1,29 \mathrm{Aa}$ & $2,83 \mathrm{Ba}$ & $1,93 \mathrm{Aa}$ & 0,25 \\
\hline \multirow{4}{*}{ Inferior } & Máximo & 0,15 & 0,51 & 0,56 & 1,4 & 14,41 & 4,65 & 0,35 \\
\hline & Mínimo & 0,01 & 0,33 & 0,39 & 1,11 & 0,01 & 0,17 & 0,19 \\
\hline & Mediana & 0,06 & 0,4 & 0,47 & 1,29 & 0,14 & 1,62 & 0,24 \\
\hline & Média & $0,06 \mathrm{Ba}$ & $0,41 \mathrm{Aa}$ & $0,47 \mathrm{Aa}$ & $1,29 \mathrm{Ba}$ & $1,68 \mathrm{Ba}$ & $1,71 \mathrm{Aa}$ & 0,26 \\
\hline \multicolumn{2}{|c|}{ Coef. Variação (\%) } & 59 & 8 & 4 & 3 & 138 & 34 & 22 \\
\hline & \multicolumn{8}{|c|}{ Áreas do Grupo 2} \\
\hline \multirow{2}{*}{\multicolumn{2}{|c|}{ Posição na encosta }} & \multicolumn{3}{|c|}{----- Porosidade $\left(\mathrm{m}^{3} \mathrm{~m}^{-3}\right)$----- } & Densidade & $\mathrm{K}(\theta)$ & RMSP & $\mathrm{Ug}$ \\
\hline & & Macro & Micro & Total & $\mathrm{Mg} \mathrm{m}^{-3}$ & $\mathrm{~cm} \mathrm{~h}^{-1}$ & $\mathrm{MPa}$ & $\mathrm{g} \mathrm{g}^{-1}$ \\
\hline \multirow{4}{*}{ Superior } & Máximo & 0,27 & 0,4 & 0,5 & 1,5 & 88,4 & 4,39 & 0,25 \\
\hline & Mínimo & 0,01 & 0,22 & 0,41 & 1,28 & 0,12 & 0,32 & 0,12 \\
\hline & Mediana & 0,13 & 0,32 & 0,45 & 1,35 & 7,2 & 1,45 & 0,18 \\
\hline & Média & $0,13 \mathrm{Aa}$ & $0,32 \mathrm{Ba}$ & $0,45 \mathrm{Aa}$ & $1,36 \mathrm{Aa}$ & $22,25 \mathrm{Aa}$ & $1,70 \mathrm{Aa}$ & 0,18 \\
\hline \multirow{4}{*}{ Médio } & Máximo & 0,22 & 0,42 & 0,5 & 1,51 & 58,93 & 3,79 & 0,27 \\
\hline & Mínimo & 0,02 & 0,18 & 0,2 & 1,24 & 0,26 & 0,51 & 0,14 \\
\hline & Mediana & 0,11 & 0,31 & 0,44 & 1,35 & 5,02 & 1,31 & 0,21 \\
\hline & Média & $0,12 \mathrm{Aab}$ & $0,31 \mathrm{Ba}$ & 0,43 Bab & 1,37 Aa & $12,43 \mathrm{Aa}$ & $1,50 \mathrm{Aa}$ & 0,21 \\
\hline \multirow{4}{*}{ Inferior } & Máximo & 0,27 & 0,42 & 0,48 & 1,52 & 134,24 & 4,12 & 0,3 \\
\hline & Mínimo & 0,01 & 0,2 & 0,36 & 1,24 & 0,05 & 0,29 & 0,1 \\
\hline & Mediana & 0,08 & 0,33 & 0,43 & 1,4 & 4,58 & 1,17 & 0,2 \\
\hline & Média & $0,09 \mathrm{Ab}$ & $0,34 \mathrm{Ba}$ & $0,42 \mathrm{Bb}$ & 1,39 Aa & $10,21 \mathrm{Aa}$ & $1,74 \mathrm{Aa}$ & 0,21 \\
\hline Coef. Var & ação (\%) & 35 & 10 & 7 & 5 & 141 & 52 & 25 \\
\hline
\end{tabular}

Em que: $\mathrm{K}(\mathrm{q})$ = Condutividade hidráulica do solo saturado; $\mathrm{RMSP}=$ Resistência mecânica do solo à penetração; Ug = Umidade gravimétrica. Para a mesma variável, valores seguidos de mesma letra na mesma coluna não diferem entre si pelo teste $\mathrm{F}$ (grupos e pedoformas) e Tukey (posição na encosta) a $5 \%$ de significância, em que letras maiúsculas e minúsculas indicam comparação, respectivamente, entre e dentro dos grupos.

No que se refere à condutividade hidráulica do solo saturado, nas áreas do Grupo 1 foram observados valores baixos, associados a altos teores de argila. Nas áreas do Grupo 2 foi observada diferença significativa dos valores de condutividade hidráulica em relação às pedoformas (Tabela 3), sendo a côncava a que apresentou maior valor. Essa propriedade é bastante influenciada pela macroporosidade do solo, 
de tal forma que pequenas alterações nos valores dessa, remetem a alterações em maiores magnitudes daquela (MARQUES et al., 2008). A diferença textural entre os grupos de solos acarretou em diferenças de porosidade e condutividade hidráulica de forma mais proeminente que o relevo (posição e forma da encosta).

A respeito da resistência mecânica do solo à penetração (RMSP), esta não foi influenciada pelas condições de relevo em ambos os grupos. De uma forma geral, as áreas em questão apresentaram valores médios abaixo do nível crítico de 2,0 MPa (COLLARES et al., 2006), valor adotado para a maioria das culturas agrícolas, acima do qual o crescimento do sistema radicular das plantas é restrito (KAISER et al., 2009).

TABELA 3: Efeito da pedoforma sobre as características físico-hídricas do solo das áreas avaliadas, Itaboraí-RJ.

TABLE 3: Effect of landform on the soil physico-hydrical characteristics of the evaluated areas, Itaboraí, RJ state.

\begin{tabular}{|c|c|c|c|c|c|c|c|c|}
\hline \multicolumn{9}{|c|}{ Áreas do Grupo 1} \\
\hline \multirow{2}{*}{ Pedoforma } & & \multicolumn{3}{|c|}{ Porosidade $\left(\mathrm{m}^{3} \mathrm{~m}^{-3}\right)$} & \multirow{2}{*}{$\begin{array}{c}\text { Densidade } \\
\mathrm{Mg} \mathrm{m}^{-3}\end{array}$} & \multirow{2}{*}{$\begin{array}{l}\mathrm{K}(\theta) \\
\mathrm{cm} \mathrm{h}^{-1}\end{array}$} & \multirow{2}{*}{$\begin{array}{c}\text { RMSP } \\
\mathrm{MPa}\end{array}$} & \multirow{2}{*}{$\begin{array}{r}\mathrm{Ug} \\
\mathrm{g} \mathrm{g}^{-1} \\
\end{array}$} \\
\hline & & Macro & Micro & Total & & & & \\
\hline \multirow{4}{*}{ Côncava } & Máximo & 0,15 & 0,49 & 0,56 & 1,39 & 16,15 & 4,65 & 0,35 \\
\hline & Mínimo & 0,01 & 0,34 & 0,42 & 1,1 & 0,01 & 0,41 & 0,19 \\
\hline & Mediana & 0,04 & 0,42 & 0,46 & 1,29 & 0,28 & 1,62 & 0,24 \\
\hline & Média & $0,05 \mathrm{Ba}$ & $0,41 \mathrm{Aa}$ & $0,46 \mathrm{Aa}$ & $1,29 \mathrm{Ba}$ & $1,94 \mathrm{Ba}$ & $1,72 \mathrm{Aa}$ & 0,26 \\
\hline \multirow{4}{*}{ Convexa } & Máximo & 0,15 & 0,51 & 0,56 & 1,4 & 19,64 & 3,49 & 0,35 \\
\hline & Mínimo & 0,01 & 0,33 & 0,39 & 1,11 & 0,01 & 0,17 & 0,19 \\
\hline & Mediana & 0,06 & 0,4 & 0,47 & 1,3 & 0,39 & 1,56 & 0,22 \\
\hline & Média & $0,06 \mathrm{Ba}$ & $0,41 \mathrm{Aa}$ & $0,47 \mathrm{Aa}$ & $1,29 \mathrm{Aa}$ & $1,91 \mathrm{Ba}$ & $1,76 \mathrm{Aa}$ & 0,25 \\
\hline \multicolumn{2}{|c|}{ Coef. Variação (\%) } & 59 & 8 & 4 & 3 & 138 & 34 & 22 \\
\hline \multicolumn{9}{|c|}{ Áreas do Grupo 2} \\
\hline \multirow{4}{*}{ Côncava } & Máximo & 0,27 & 0,4 & 0,5 & 1,52 & 134,24 & 3,67 & 0,27 \\
\hline & Mínimo & 0,01 & 0,2 & 0,36 & 1,24 & 0,51 & 0,05 & 0,1 \\
\hline & Mediana & 0,13 & 0,31 & 0,45 & 1,36 & 7,75 & 1,23 & 0,2 \\
\hline & Média & $0,12 \mathrm{Aa}$ & $0,31 \mathrm{Bb}$ & $0,43 \mathrm{Ba}$ & $1,39 \mathrm{Aa}$ & $18,01 \mathrm{Aa}$ & $1,51 \mathrm{Aa}$ & 0,19 \\
\hline \multirow{4}{*}{ Convexa } & Máximo & 0,21 & 0,42 & 0,49 & 1,51 & 88,4 & 4,39 & 0,3 \\
\hline & Mínimo & 0,01 & 0,18 & 0,2 & 1,28 & 0,12 & 0,29 & 0,13 \\
\hline & Mediana & 0,09 & 0,33 & 0,43 & 1,38 & 2,71 & 1,4 & 0,2 \\
\hline & Média & $0,10 \mathrm{Aa}$ & $0,33 \mathrm{Ba}$ & $0,44 \mathrm{Ba}$ & $1,36 \mathrm{Ab}$ & $11,92 \mathrm{Ab}$ & $1,78 \mathrm{Aa}$ & 0,2 \\
\hline \multicolumn{2}{|c|}{ Coef. Variação (\%) } & 35 & 10 & 7 & 5 & 141 & 52 & 25 \\
\hline
\end{tabular}

Em que: $\mathrm{K}(\mathrm{q})$ = Condutividade hidráulica do solo saturado; $\mathrm{RMSP}=$ Resistência mecânica do solo à penetração; Ug = Umidade gravimétrica. Para a mesma variável, valores seguidos de mesma letra na mesma coluna não diferem entre si pelo teste $\mathrm{F}$ (grupos e pedoforma) e Tukey (posição na encosta) a $5 \%$ de significância, em que letras maiúsculas e minúsculas indicam comparação, respectivamente, entre e dentro dos grupos.

\section{Atributos químicos do solo}

As condições de relevo pouco influenciaram os atributos químicos do solo (Tabela 4). $\mathrm{O}$ pH para ambos os grupos apresentou acidez potencial, de média a alta (ALVAREZ et al., 1999), não sendo observadas diferenças significativas entre as posições na encosta e pedoforma, tampouco entre os grupos. A saturação por alumínio ( $\mathrm{m} \%$ ) também não foi influenciada pelas condições de relevo. Os valores de SB foram baixos e os de T médios, para os dois grupos, o que remete à baixa saturação por bases (V \%). Nota-se ainda que a 
posição na encosta pouco influenciou esses resultados (SB e T).

Os teores de carbono no solo apresentaram níveis de baixos a bom (ALVAREZ et al., 1999), não sendo influenciados pelas condições de relevo. No que se refere à pedoforma, a convexa nas áreas do Grupo 1 apresentou maiores valores de carbono, sendo significativamente superior aos encontrados na pedoforma côncava. Esse fato pode ser devido à maior concentração preferencial dos fluxos hídricos pluviais (superficial e subsuperficial) que ocorrem na pedoforma côncava (RIBEIRO; SALOMÃO, 2003), favorecendo a maior remoção nesses locais. Com relação ao nitrogênio, nas áreas do Grupo 1 os teores desse elemento apresentaram-se condizentes com a dinâmica do carbono, visto que a relação $\mathrm{C} / \mathrm{N}$ da matéria orgânica do solo é relativamente constante. A pedoforma côncava, embora tenha apresentado tendência de menor fertilidade que a pedoforma convexa nos dois grupos, só teve essa diferença expressada de forma significativa para a soma de bases e o carbono do solo, nas áreas de textura argilosa (Grupo 1).

A baixa fertilidade desses solos é herança do sistema de manejo e exploração das atividades pretéritas, uma vez que o manejo sem a reposição de nutrientes nas pastagens e com a queima anual levam à rápida mineralização de nutrientes (REDIN et al., 2011).

TABELA 4: Efeito da posição na encosta e da pedoforma sobre as características químicas dos solos das áreas estudadas, Itaboraí-RJ.

TABLE 4: Effect of toposequence position and landform on soil chemical characteristics of the studied areas, Itaboraí, RJ state.

\begin{tabular}{|c|c|c|c|c|c|c|c|c|}
\hline \multirow{3}{*}{ Posição na encosta } & \multicolumn{6}{|c|}{ Áreas do Grupo 1} & \multirow[b]{2}{*}{$\mathrm{N}$} & \multirow[b]{2}{*}{$\mathrm{C}: \mathrm{N}$} \\
\hline & $\mathrm{pH}$ & $\mathrm{m}$ & SB & $\mathrm{T}$ & $\mathrm{V}$ & $\mathrm{C}$ & & \\
\hline & & $\%$ & \multicolumn{2}{|c|}{---- $\mathrm{cmol}_{\mathrm{c}} \mathrm{dm}^{-3}----$} & \multicolumn{3}{|c|}{-------- \% -------- } & \\
\hline T. Superior & $4,26 \mathrm{Aa}$ & $56 \mathrm{Aa}$ & $0,92 \mathrm{Aa}$ & $6,20 \mathrm{Aa}$ & $14 \mathrm{Aa}$ & $1,39 \mathrm{Aa}$ & $0,13 \mathrm{Aa}$ & $11,2 \mathrm{Aa}$ \\
\hline T. Médio & $4,10 \mathrm{Aa}$ & $72 \mathrm{Aa}$ & $0,56 \mathrm{Aa}$ & $6,20 \mathrm{Aa}$ & $9 \mathrm{Aa}$ & $1,42 \mathrm{Aa}$ & $0,13 \mathrm{Aa}$ & $11,3 \mathrm{Aa}$ \\
\hline T. Inferior & $4,13 \mathrm{Aa}$ & $74 \mathrm{Aa}$ & $0,53 \mathrm{Aa}$ & $6,11 \mathrm{Aa}$ & $8 \mathrm{Aa}$ & $1,20 \mathrm{Aa}$ & $0,12 \mathrm{Aa}$ & $10,2 \mathrm{Aa}$ \\
\hline \multicolumn{9}{|l|}{ Pedoforma } \\
\hline Côncava & 4,08 Aa & $77 \mathrm{Aa}$ & $0,42 \mathrm{Ab}$ & 5,99 Aa & $7 \mathrm{Aa}$ & $1,26 \mathrm{Ab}$ & $0,12 \mathrm{Aa}$ & $10,8 \mathrm{Aa}$ \\
\hline Convexa & 4,24 Aa & $57 \mathrm{Aa}$ & $0,93 \mathrm{Aa}$ & 6,34 Aa & $14 \mathrm{Aa}$ & $1,41 \mathrm{Aa}$ & $0,13 \mathrm{Aa}$ & $10,9 \mathrm{Aa}$ \\
\hline Coef. Variação (\%) & 6 & 35 & 88 & 19 & 79 & 18 & 25 & 20 \\
\hline \multicolumn{9}{|c|}{ Áreas do Grupo 2} \\
\hline \multirow{2}{*}{ Posição na encosta } & $\mathrm{pH}$ & $\mathrm{m}$ & SB & $\mathrm{T}$ & $\mathrm{V}$ & $\mathrm{C}$ & $\mathrm{N}$ & $\mathrm{C}: \mathrm{N}$ \\
\hline & & $\%$ & \multicolumn{2}{|c|}{---- $\mathrm{cmol}_{\mathrm{c}} \mathrm{dm}^{-3}$} & \multicolumn{3}{|c|}{--------- \% ------------ } & \\
\hline T. Superior & 4,24 Aa & $76 \mathrm{Aa}$ & $0,43 \mathrm{Aa}$ & 5,69 Aa & $7 \mathrm{Aa}$ & $1,08 \mathrm{Aa}$ & $0,10 \mathrm{Aa}$ & $11,3 \mathrm{Aa}$ \\
\hline T. Médio & 4,30 Aa & $69 \mathrm{Aa}$ & $0,50 \mathrm{Aa}$ & $5,65 \mathrm{Aa}$ & $8 \mathrm{Aa}$ & $1,07 \mathrm{Aa}$ & $0,10 \mathrm{Aa}$ & $10,4 \mathrm{Aa}$ \\
\hline T. Inferior & 4,20 Aa & $65 \mathrm{Aa}$ & $0,68 \mathrm{Aa}$ & 5,90 Aa & $12 \mathrm{Aa}$ & $1,08 \mathrm{Aa}$ & $0,11 \mathrm{Aa}$ & $10,0 \mathrm{Aa}$ \\
\hline \multicolumn{9}{|l|}{ Pedoforma } \\
\hline Côncava & $4,24 \mathrm{Aa}$ & $68 \mathrm{Aa}$ & $0,45 \mathrm{Aa}$ & 5,33 Aa & $8 \mathrm{Aa}$ & $1,02 \mathrm{Aa}$ & $0,10 \mathrm{Aa}$ & $10,0 \mathrm{Aa}$ \\
\hline Convexa & $4,25 \mathrm{Aa}$ & $72 \mathrm{Aa}$ & $0,63 \mathrm{Aa}$ & $6,16 \mathrm{Aa}$ & $10 \mathrm{Aa}$ & $1,13 \mathrm{Aa}$ & $0,10 \mathrm{Aa}$ & $11,1 \mathrm{Aa}$ \\
\hline Coef. Variação (\%) & 6 & 46 & 115 & 24 & 102 & 18 & 15 & 15 \\
\hline
\end{tabular}

Em que: $\mathrm{m}=$ saturação por alumínio; $\mathrm{SB}=$ soma de bases; $\mathrm{T}=\mathrm{CTC}$ pH 7; $\mathrm{V}=$ saturação por bases; $\mathrm{C}=$ Carbono; $\mathrm{N}$ = nitrogênio. Para a mesma variável, valores seguidos de mesma letra não diferem entre si pelo teste $\mathrm{F}$ (grupos $\mathrm{e}$ pedoforma) e Tukey (posição na encosta) a $5 \%$ de significância, em que letras maiúsculas e minúsculas indicam comparação, respectivamente, entre e dentro dos grupos. 


\section{Biomassa e taxa de rebrota das forrageiras}

Das gramíneas predominantes na pastagem, a Urochloa humidicola e a Paspalum sp. apresentaram maior ocorrência em relação a Urochloa decumbens, havendo similaridades quanto a distribuição dessas espécies nos dois grupos. A produtividade da biomassa aérea dessas espécies apresentou altos valores, superando $10 \mathrm{Mg} \mathrm{ha}^{-1}$, chegando em torno de $14 \mathrm{Mg} \mathrm{ha}^{-1}$ no caso das espécies Urochloa humidicola e Urochloa decumbens (Tabela 5).

Os valores de biomassa da parte aérea não diferiram estatisticamente entre pedoformas dentro de cada grupo. Entre os grupos, para as mesmas pedoformas e posições na encosta, as áreas de textura média (Grupo 2) apresentaram maiores valores de rebrota que as áreas argilosas, com uma tendência das áreas côncavas apresentarem os menores valores, principalmente nos pontos mais altos da paisagem. Os resultados indicam que a classe textural se mostrou mais determinante da taxa de rebrota das espécies forrageiras do que os demais fatores ligados às condições química e físico-hídrica dos solos, excetuando-se a macroporosidade e condutividade hidráulica.

TABELA 5: Valores médios de biomassa seca estocada e taxa de rebrota da pastagem nas áreas estudadas, Itaboraí-RJ. TABLE 5: Mean values of stocked dry biomass and pasture regrowth rate in the studied areas, Itaboraí, RJ state.

\begin{tabular}{|c|c|c|c|c|c|c|}
\hline \multicolumn{7}{|c|}{ Biomassa aérea da pastagem em $\mathrm{Mg} \mathrm{ha}^{-1}$} \\
\hline \multirow{3}{*}{ Posição na encosta } & \multicolumn{3}{|c|}{ Áreas do Grupo 1} & \multicolumn{3}{|c|}{ Áreas do Grupo 2} \\
\hline & \multicolumn{2}{|c|}{ Pedoforma } & \multicolumn{4}{|c|}{ Pedoforma } \\
\hline & Côncava & Convexa & Média & Côncava & Convexa & Média \\
\hline Superior & 11,9 & 12,5 & $12,2 \mathrm{Aab}$ & 12,4 & 11,4 & $11,9 \mathrm{Aa}$ \\
\hline Médio & 14,2 & 13 & $13,6 \mathrm{Aa}$ & 9,7 & 11,7 & $10,7 \mathrm{Ba}$ \\
\hline Inferior & 10 & 11,7 & $10,9 \mathrm{Ab}$ & 12,2 & 11,9 & $12,0 \mathrm{Aa}$ \\
\hline Média & $12,0 \mathrm{Aa}$ & $12,4 \mathrm{Aa}$ & 12,2 & $11,4 \mathrm{Aa}$ & $11,7 \mathrm{Aa}$ & 11,5 \\
\hline \multicolumn{7}{|c|}{ Taxa de rebrota da pastagem em $\mathrm{kg} \mathrm{ha}^{-1} \mathrm{dia}^{-1}$} \\
\hline \multirow{3}{*}{ Posição na encosta } & \multicolumn{3}{|c|}{ Áreas do Grupo 1} & \multicolumn{3}{|c|}{ Áreas do Grupo 2} \\
\hline & \multicolumn{2}{|c|}{ Pedoforma } & \multicolumn{4}{|c|}{ Pedoforma } \\
\hline & Côncava & Convexa & Média & Côncava & Convexa & Média \\
\hline Superior & 35,2 & 43,2 & $39,2 \mathrm{Aa}$ & 39,2 & 44,8 & $42,0 \mathrm{Aa}$ \\
\hline Médio & 23,2 & 33,6 & $28,4 \mathrm{Ba}$ & 38,4 & 55,6 & $46,8 \mathrm{Aa}$ \\
\hline Inferior & 29,6 & 32,8 & $31,2 \mathrm{Ba}$ & 48 & 45,6 & $46,8 \mathrm{Aa}$ \\
\hline Média & $29,2 \mathrm{Ba}$ & $36,4 \mathrm{Ba}$ & 32,8 & $41,6 \mathrm{Aa}$ & $48,8 \mathrm{Aa}$ & 45,2 \\
\hline
\end{tabular}

Valores seguidos de mesma letra na mesma coluna e linha não diferem entre si pelo teste $\mathrm{F}$ (grupos e pedoforma) e Tukey (posição na encosta) a $5 \%$ de significância, em que letras maiúsculas e minúsculas indicam comparação entre e dentro dos grupos, respectivamente.

\section{Regeneração Natural nas Áreas Avaliadas}

A respeito da regeneração herbáceo-arbustiva foram identificadas nove famílias nas áreas do Grupo 1 (Asteraceae, Boraginaceae, Euphorbiaceae, Leguminosae, Malvaceae, Melastomataceae, Polipodiaceae, Solanaceae e Indeterminada) e oito nas do Grupo 2 (Asteraceae, Euphorbiaceae, Lamiaceae, Malvaceae, Melastomataceae, Rubiaceae, Solanaceae e Indeterminada), não sendo observadas diferenças significativas entre os parâmetros utilizados na descrição desse estrato entre as condições de relevo e grupos de áreas avaliados (Tabela 6).

A família Asteraceae apresentou-se mais predominante, representando, para ambos os grupos, 
cerca de $40 \%$ das espécies encontradas. Vale ressaltar que dentre as espécies dessa família, as dos gêneros Vernonia, Eupatorium e Chaptalia são descritas como bastante agressivas (SANTOS JUNIOR et al., 2010), rústicas, tolerando solos de baixa fertilidade e ácidos além de se recuperarem após queimada, sendo comuns em áreas de pastagens. Essas características se tornam favoráveis ao processo de sucessão nesses ambientes uma vez que o ingresso inicial dessas espécies tende a favorecer o estabelecimento da regeneração natural arbórea. Isso pode indicar que em programas de reflorestamento, que normalmente ocorrem em áreas com características físicas e químicas do solo depauperadas, não somente o estrato arbóreo deva ser considerado na ocasião do plantio, mas também o herbáceo-arbustivo (PELLIZZARO et al., 2017).

Quanto às espécies arbóreas, foram identificadas nove famílias nas áreas do Grupo 1 (Anacardiaceae, Asteraceae, Bignoniaceae, Euphorbiaceae, Leguminosae, Melastomataceae, Myrsinaceae, Myrtaceae e Indeterminada) e seis nas do Grupo 2 (Apocynaceae, Asteraceae, Bignoniaceae, Leguminosae, Myrtaceae e Indeterminada). A maioria das famílias encontradas é relatada por outros autores em trabalhos descrevendo a dinâmica da regeneração natural em áreas em recuperação após abandono (VIEIRA; PESSOA, 2001; CHEUNG; MARQUES; LIEBSCH, 2009). Espécies das famílias Asteraceae e Bignoniaceae, comuns aos dois grupos, são eficientemente disseminadas (anemocóricas) e bastante comuns em estádios iniciais de sucessão.

Para a dominância e riqueza não foram observadas diferenças significativas nas distintas posições na encosta e pedoforma, entre os dois grupos (Tabela 6). De forma geral, a regeneração dessas áreas ainda se encontra em fase inicial, com baixa riqueza de espécies. Levando-se em consideração a alta variabilidade dos dados encontrados, o que é comum em se tratando de regeneração natural em fase inicial. Isso dificulta a distinção da influência das condições de relevo no padrão da regeneração apresentado, havendo a necessidade de ampliar o universo amostral no tempo ou com novas áreas.

TABELA 6: Quantificação da regeneração natural nas áreas de estudo, Itaboraí-RJ.

TABLE 6: Natural regeneration quantification in the study areas, Itaboraí, RJ state.

\begin{tabular}{|c|c|c|c|c|c|c|}
\hline \multirow{3}{*}{$\begin{array}{l}\text { Áreas do Grupo } 1 \\
\text { Posição na encosta }\end{array}$} & \multicolumn{3}{|c|}{ Herbáceo-arbustiva } & \multicolumn{3}{|c|}{ Arbórea } \\
\hline & \multirow{2}{*}{$\frac{\text { Cobertura }}{\left(\mathrm{m}^{2} \mathrm{ha}^{-1}\right)}$} & \multicolumn{2}{|c|}{ Riqueza } & \multirow{2}{*}{$\frac{\text { Dominância }}{\left(\mathrm{cm}^{2} \mathrm{ha}^{-1}\right)}$} & \multicolumn{2}{|c|}{ Riqueza } \\
\hline & & Média & Total & & Média & Total \\
\hline Superior & $885,9 \mathrm{Aa}$ & $3,8 \mathrm{Aa}$ & 14 & $102,7 \mathrm{Aa}$ & $2,4 \mathrm{Aa}$ & 6 \\
\hline Médio & $920,3 \mathrm{Aa}$ & $3,1 \mathrm{Aa}$ & 11 & $126,5 \mathrm{Aa}$ & $1,6 \mathrm{Aa}$ & 8 \\
\hline Inferior & $1082,8 \mathrm{Aa}$ & 3,6 Aa & 17 & $58,1 \mathrm{Aa}$ & $1,8 \mathrm{Aa}$ & 9 \\
\hline \multicolumn{7}{|l|}{ Pedoforma } \\
\hline Côncava & $1157,3 \mathrm{Aa}$ & $3,3 \mathrm{Aa}$ & 14 & $148,4 \mathrm{Aa}$ & $2,0 \mathrm{Aa}$ & 9 \\
\hline Convexa & $768,8 \mathrm{Aa}$ & $3,7 \mathrm{Aa}$ & 17 & $43,2 \mathrm{Aa}$ & $1,8 \mathrm{Aa}$ & 10 \\
\hline Coef. Variação & 104 & 78 & & 151 & 75 & \\
\hline Áreas do Grupo 2 & \multicolumn{3}{|c|}{ Herbáceo-arbustiva } & \multicolumn{3}{|c|}{ Arbórea } \\
\hline \multirow{2}{*}{ Posição na encosta } & Cobertura & \multicolumn{2}{|c|}{ Riqueza } & Dominância & \multicolumn{2}{|c|}{ Riqueza } \\
\hline & $\left(\mathrm{m}^{2} \mathrm{ha}^{-1}\right)$ & Média & Total & $\left(\mathrm{cm}^{2} \mathrm{ha}^{-1}\right)$ & Média & Total \\
\hline Superior & $1173,4 \mathrm{Aa}$ & $5,3 \mathrm{Aa}$ & 14 & $85,6 \mathrm{Aa}$ & $1,0 \mathrm{Aa}$ & 7 \\
\hline Médio & $1617,2 \mathrm{Aa}$ & $4,8 \mathrm{Aa}$ & 13 & $15,9 \mathrm{Aa}$ & $1,1 \mathrm{Aa}$ & 5 \\
\hline Inferior & $1582,8 \mathrm{Aa}$ & $5,1 \mathrm{Aa}$ & 11 & $12,5 \mathrm{Aa}$ & $1,4 \mathrm{Aa}$ & 7 \\
\hline \multicolumn{7}{|l|}{ Pedoforma } \\
\hline Côncava & $1393,8 \mathrm{Aa}$ & $4,8 \mathrm{Aa}$ & 13 & $68,0 \mathrm{Aa}$ & $1,5 \mathrm{Aa}$ & 8 \\
\hline Convexa & $1521,9 \mathrm{Aa}$ & $5,3 \mathrm{Aa}$ & 15 & $8,0 \mathrm{Aa}$ & $0,8 \mathrm{Aa}$ & 7 \\
\hline Coef. Variação & 75 & 52 & & 251 & 109 & \\
\hline
\end{tabular}

Valores seguidos de mesma letra na mesma coluna não diferem entre si pelo teste $\mathrm{F}$ (grupos e pedoforma) e Tukey (posição na encosta) a $5 \%$ de significância, em que letras maiúsculas e minúsculas indicam comparação, respectivamente, entre e dentro dos grupos. 
Associando as espécies forrageiras à regeneração natural das espécies florestais, nota-se que essas oferecem diferentes níveis de resistência para o avanço nessa fase da sucessão ecológica (Tabela 7). Menores valores de cobertura de indivíduos herbáceo-arbustivo e riqueza de espécies arbórea e herbáceoarbustiva foram observados em áreas com predomínio de Urochloa humidicola. Essas restrições são destacadas em outros estudos de regeneração em áreas de pastagem abandonadas (CHEUNG; MARQUES; LIEBSCH, 2009), o que remete à importância do uso dessas informações no planejamento de programas de reflorestamento. Pelo que parece, o capim predominante na matriz é fundamental para ditar o ritmo da regeneração natural (MANTOANI; TOREZAN, 2016), demonstrando ser um indicador mais sensível, barato e fácil de ser mensurado do que as características químicas e físico hídricas do solo, que se mostraram indicadores menos sensíveis.

Os resultados dos valores da soma de bases e carbono do solo e da taxa de rebrota de capim, na pedoforma côncava, possibilitam explicar o porquê de ser nesses locais que a regeneração natural sempre se inicia em condições naturais. Por ter menor fertilidade, a taxa de rebrota do capim é menos vigorosa nesse ponto da paisagem, dando oportunidade para que espécies herbáceas, arbustivas e arbóreas, de folha larga, consigam competir melhor com essas gramíneas e se estabelecer. Isso, aliado ao fato de a pedoforma côncava ser uma zona de recebimento de água e sementes de outros pontos da paisagem, justifica a regeneração mais intensa nessas pedoformas, do que nas convexas.

TABELA 7: Indicadores da regeneração natural de espécies arbóreas e herbáceo-arbustivas em função das espécies forrageiras na matriz pastagem, Itaboraí-RJ.

TABLE 7: Indicators of the natural regeneration of arboreal and herbaceous-shrub species as a function of the forage species in the pasture matrix, Itaboraí, RJ state.

\begin{tabular}{ccccc}
\hline \multirow{2}{*}{ Espécie } & ---------- Arbórea ---------- & \multicolumn{2}{c}{------ Herbáceo-arbustiva ------- } \\
& Dominância $\left(\mathrm{cm}^{2} \mathrm{ha}^{-1}\right)$ & Riqueza média & Cobertura $\left(\mathrm{m}^{2} \mathrm{ha}^{-1}\right)$ & Riqueza média \\
\hline Urochloa decumbens & $13,7 \mathrm{a}$ & $1,9 \mathrm{a}$ & $1069,6 \mathrm{ab}$ & $5,7 \mathrm{a}$ \\
Urochloa humidicola & $80,8 \mathrm{a}$ & $0,6 \mathrm{~b}$ & $295,5 \mathrm{~b}$ & $2,6 \mathrm{~b}$ \\
Paspalum sp. & $73,5 \mathrm{a}$ & $1,9 \mathrm{a}$ & $1721,3 \mathrm{a}$ & $4,7 \mathrm{ab}$ \\
\hline Coef. Variação & 251,45 & 109,2 & 74,82 & 51,81 \\
\hline
\end{tabular}

*Valores seguidos de mesma letra na mesma coluna não diferem entre si pelo teste de Tukey a $5 \%$ de significância.

\section{CONCLUSÃO}

A regeneração natural de espécies arbóreas e herbáceo-arbustivas é mais limitada pela presença da Urochloa humidicola quando comparada com outras espécies de forrageiras. Esse fator se mostrou um indicador mais determinante do potencial de regeneração da área do que características químicas e físico- 
hídricas do solo, independentemente da posição na encosta. A pedoforma côncava, por apresentar menor valor de soma de bases e carbono do solo além de uma taxa de rebrota mais lenta da gramínea, possibilita o surgimento mais acelerado da regeneração natural do que a pedoforma convexa.

\section{AGRADECIMENTOS}

Os autores agradecem aos técnicos Fernando Cunha e Telmo Félix (in memoriam), a Embrapa Agrobiologia, ao Departamento de Solos - UFRRJ, pela infraestrutura e suporte, e ao Conselho Nacional de Desenvolvimento Científico e Tecnológico (CNPq), pelo auxílio financeiro.

\section{REFERÊNCIAS}

ALVAREZ, V. H. et al. Interpretação dos resultados das análises de solos. In: RIBEIRO, A. C.; GUIMARÃES, P. T. G.; ALVAREZ, V. H. (Ed.). Recomendação para o uso de corretivos e fertilizantes em Minas Gerais: 5. Aproximação. Viçosa, MG: CFSEMG; Imprensa Universitária UFV, 1999. p. 25-32.

CHEUNG, K. C.; MARQUES, M. C. M.; LIEBSCH, D. Relação entre a presença de vegetação herbácea e a regeneração natural de espécies lenhosas em pastagens abandonadas na Floresta Ombrófila Densa do Sul do Brasil. Acta Botanica Brasilica, Belo Horizonte, v. 23, n. 4, p. 1048-1056, 2009.

COLLARES, G. L. et al. Qualidade física do solo na produtividade da cultura do feijoeiro num Argissolo. Revista Pesquisa Agropecuária Brasileira, Brasília, v. 41, n. 11, p. 1663-1674, 2006.

CURCIO, G. R. et al. Compartimentação topossequencial e caracterização fitossociológica de um capão de Floresta Ombrófila Mista. Floresta, Curitiba, v. 36, n. 3, p. 361-369, 2006.

EMBRAPA. Centro Nacional de Pesquisa em Solos. Manual de métodos de análise de solo. 2. ed. rev. atual. Rio de Janeiro: EMBRAPA, 1997. 212 p.

FERREIRA, W. C. et al. Avaliação do crescimento do estrato arbóreo de área degradada revegetada à margem do Rio Grande, na Usina Hidrelétrica de Camargos, MG. Revista Árvore, Viçosa, MG, v. 31, n. 1, p. 177-185, 2007.

GOMES, J. B. V. et al. Atributos químicos e mineralógicos dos solos. In.: PRADO, R. B.; FIDALGO, E. C. C.; BONNET, A. (Ed.). Monitoramento da revegetação do COMPERJ: etapa inicial. 1. ed. Brasília: Embrapa, 2014. p. 103-118.

KAISER, D. R. et al. Intervalo hídrico ótimo no perfil explorado pelas raízes de feijoeiro em um Latossolo sob diferentes níveis de compactação. Revista Brasileira de Ciência do Solo, Viçosa, MG, v. 33, p. 845-855, 2009.

MANTOANI, M. C.; TOREZAN, J. M. D. Regeneration response of Brazilian Atlantic Forest woody species to four years of Megathyrsus maximus removal. Forest Ecology and Management, Amsterdam, v. 359, n. 1, p. 141-146, 2016.

MARQUES, J. D. O. et al. Avaliação da condutividade hidráulica do solo saturada utilizando dois métodos de laboratório numa topossequência com diferentes coberturas vegetais no Baixo Amazonas. Acta Amozonica, Manaus, v. 38, n. 2, p. 193-206, 2008.

PELLIZZARO, K. F. et al. "Cerrado" restoration by direct seeding: field establishment and initial growth of 75 trees, shrubs and grass species. Brazilian Journal of Botany, São Paulo, p. 1-13, 2017.

REDIN, M. et al. Impactos da queima sobre atributos químicos, físicos e biológicos do solo. Ciência Florestal, Santa Maria, v. 21, n. 2, p. 381-392, 2011.

RIBEIRO, J. C.; SALOMÃO, F. X. Abordagem morfopedológica aplicada ao diagnóstico e prevenção de processos erosivos na Bacia Hidrográfica do Alto Rio da Casca, MT. Geociências, Rio Claro, v. 22, n. 1, p. 83-95, 2003.

RUIZ, H. A. Incremento da exatidão da análise granulométrica do solo por meio da coleta da suspensão (silte + argila). Revista Brasileira de Ciência do Solo, Viçosa, MG, v. 29, n. 2, p. 297-300, 2005. 
SANTOS, G. L. et al. Landform curvature and its effect on the spatial variability of soil attributes, PinheiralRJ/BR. Cerne, Lavras, v. 22, n. 4, p. 431-438, 2016.

SANTOS, R. D. et al. Manual de descrição e coleta de solo no campo. 5. ed. Viçosa, MG: Folha de Viçosa, 2005. $100 \mathrm{p}$.

SANTOS JUNIOR, N. A. et al. Colonização natural por espécies nativas e exóticas das encostas degradadas da Serra do Mar. Revista Árvore, Viçosa, MG, v. 34, p. 267-276, 2010.

SOUZA, P. B. Diversidade Florística e atributos pedológicos ao longo de uma encosta com floresta estacional semidecidual submontana, zona de amortecimento do Parque Estadual do Rio Doce, MG. 2008. 138 f. Tese (Doutorado em Botânica) - Universidade Federal de Viçosa, Viçosa, MG, 2008.

VIEIRA, C. M.; PESSOA, S. V. A. Estrutura e composição florística do estrato herbáceo-arbustivo de um pasto abandonado na Reserva Biológica de Poço das Antas, município de Silva Jardim, RJ. Rodriguésia, Rio de Janeiro, v. 52, n. 80, p. 17-30. 2001. 